
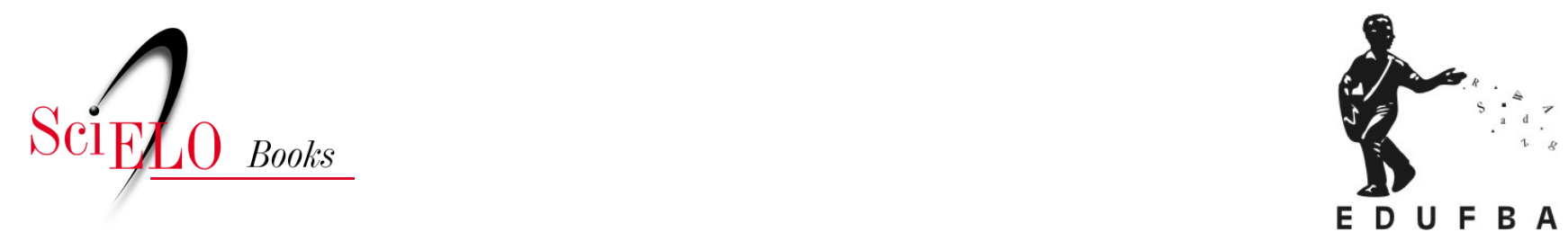

\title{
Antecedentes e questões em disputa relativos à construção dos problemas bucais até 1989
}

\author{
Thais Regis Aranha Rossi
}

\section{SciELO Books / SciELO Livros / SciELO Libros}

ROSSI, T.R.A. Antecedentes e questões em disputa relativos à construção dos problemas bucais até 1989. In: Produção social das políticas de saúde bucal no Brasil [online]. Salvador: EDUFBA, 2018, pp. 45-64. ISBN 978-85-232-2022-8. https://doi.org/10.7476/9788523220228.0003.

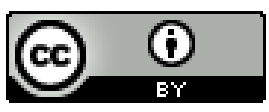

All the contents of this work, except where otherwise noted, is licensed under a Creative Commons Attribution 4.0 International license.

Todo o conteúdo deste trabalho, exceto quando houver ressalva, é publicado sob a licença Creative Commons Atribição 4.0. 


\section{ANTECEDENTES E QUESTÕES EM DISPUTA RELATIVOS À CONSTRUÇÃO DOS PROBLEMAS BUCAIS ATÉ 1989}

Neste capítulo, pretendemos abordar os antecedentes e questões que estavam em disputa até a década de 1980. No período anterior a 1989, têm sido descritas iniciativas estatais voltadas para alguns problemas bucais, principalmente sob a forma de políticas verticalizadas, desarticuladas entre si e com períodos relativamente curtos de vigência.

A partir de 1922, através da Lei Eloy Chaves, iniciou-se a prestação organizada de serviços de saúde previdenciária através das Caixas de Aposentadorias e Pensões (CAP), com oferta esporádica de serviços odontológicos a alguns segmentos de trabalhadores urbanos. (MOYSÉS, 2014) A partir da criação dos Institutos de Aposentadorias e Pensões (IAP), ocorreu o crescimento das modalidades de compra de serviços do mercado em detrimento da expansão dos serviços próprios. (ZANETTI, 1993) Os odontólogos eram remunerados para tratar dos beneficiários da previdência em seus consultórios, mediante tabela de valores previamente acordada. (PINTO, 1993) Este processo se pautou por orientações administrativas definidas de forma autoritária e centralizada (ZANETTI, 1993) sem o estabelecimento de diretrizes e/ou normas técnicas (VIANNA, 1988) (Figura 1).

No que tange às ações do Ministério da Saúde, na década de 1950, verificou-se a introdução de um modelo misto que envolvia ações tanto curativas como preventivas de inspiração no modelo norte-americano que centrava suas ações em escolares regularmente matriculados, cabendo aos adultos apenas atendimento de urgência. (FSESP, 1971; OPAS, 2006)

O primeiro manual impresso com Normas Técnicas de Odontologia Sanitária foi editado pela Fundação Serviços de Saúde Pública (FSESP), em 1963, no Rio de Janeiro. A política, de cunho nacional, baseada no sistema incremental trazia o atendimento prioritário aos escolares, com possibilidade de considerar alguns casos 


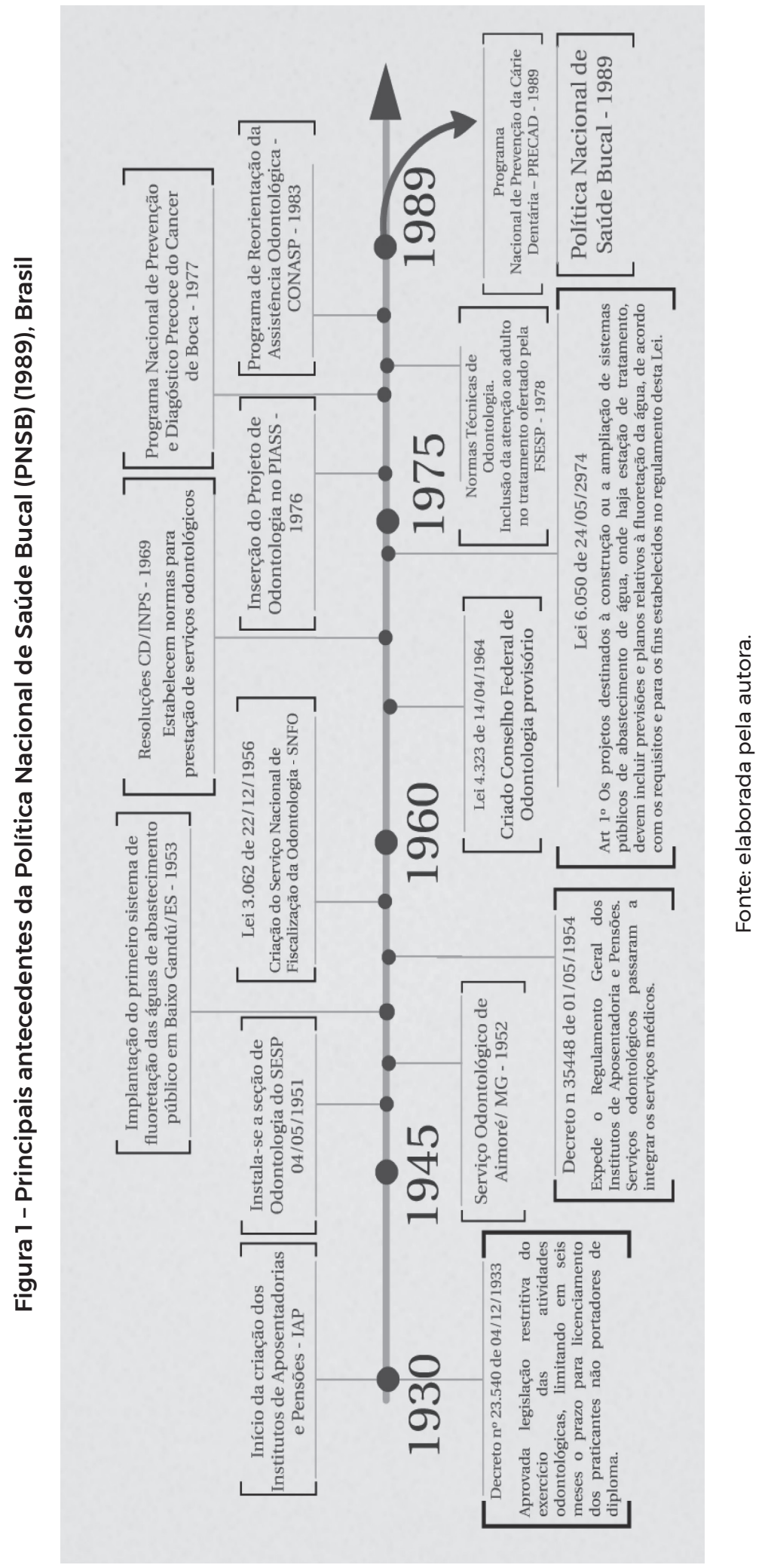

46 / Thais Regis Aranha Rossi 
especiais para atendimento a gestantes e outros, uso de consultórios semiportáteis e utilização de pessoal auxiliar. (FSESP, 1963)

O método preconizado para o exame clínico nas escolas era semelhante aos inquéritos epidemiológicos, fora do consultório, preferencialmente nos pátios. A partir dos exames, se estabeleciam as prioridades dentro do plano incremental de atendimentos a seguir detalhado. O trabalho deveria ser iniciado nas escolas com maior número de matrículas e melhores condições de trabalho. Os resultados da avaliação inicial indicavam as prioridades. Inicialmente, todas as crianças de sete a oito anos e as de seis anos, caso existissem na escola. Nos anos subsequentes, eram escolhidos grupos não selecionados, até que se fizesse necessário o atendimento de manutenção.

No Boletim Diário de Produção e no Relatório Mensal deveriam constar três partes:

- tratamento recuperador a escolares (comparecimentos do paciente ao atendimento, exames dentários, tratamentos completados, ${ }^{11}$ registro apenas dos dentes permanentes, superfícies obturadas em amálgama ou silicato, capeamentos e forramentos e horas trabalhadas);

- tratamento profilático - fluorterapia: (comparecimentos, profilaxias limpezas feitas antes da primeira aplicação de flúor, tratamentos completados - sequência de quatro aplicações de flúor no intervalo máximo de uma semana, horas trabalhadas);

- tratamento radical (comparecimentos dos pacientes que realizaram exodontias, número de elementos extraídos e horas trabalhadas). O manual continha normas para avaliação, treinamento e seleção de pessoal e anexos com os instrumentos a serem preenchidos pelos dentistas da FSESP em serviço, assim como instruções para seu devido preenchimento. Contemplava, também, as normas do treinamento de pessoal.

Quanto ao pessoal auxiliar, um dos conteúdos era a técnica correta de escovação, tendo em vista que estes desenvolviam atividades educativas com pequenos grupos. (FSESP, 1963)

No que diz respeito à Previdência, em 26 de agosto de 1960 (BRASIL, 1960) foi promulgada a Lei Orgânica da Previdência Social (LOPS) que uniformizava o funcionamento e financiamento dos IAP (COHN, 1995), tratava genericamente da

11 Os tratamentos completados deveriam ser realizados em todos os serviços necessários constatados ao exame dentário. (FSESP, 1963) 
prestação de serviços de proteção da saúde. A prestação da assistência odontológica para os beneficiários em geral é incluída na lei, em 1973.

Diretrizes específicas destinadas a orientar a prática odontológica, de acordo com recomendação do Conselho Diretor do Departamento Nacional de Previdência Social foram fixadas em 1969. A assistência previdenciária odontológica proporcionava uma quantidade reduzida de procedimentos, sendo admitida variações de instituto para instituto (IAP) que, depois, foram unificados no INPS, o que trouxe expansão nos serviços e menores discrepâncias no nível nacional, conforme já apontado no trabalho de Vianna (1988) e Pinto (1993). Havia um predomínio de ações curativas, em detrimento de ações de prevenção. O procedimento mais executado eram as extrações dentárias. A cobertura dos serviços odontológicos era baixa dentre a população de segurados.

Um relatório de desempenho da FSESP em 30 anos apontou experiências exitosas quanto à fluoretação das águas de sistemas públicos de abastecimento, com redução de $65 \%$ na incidência de cárie dentária nas populações beneficiadas. (FSESP, 1972) A fluoretação foi implementada em Baixo Guandu, no estado do Espírito Santo, em 1953 e, ao final de 1972, existiam 41 sistemas implantados, beneficiando 733.000 pessoas. (FSESP, 1972) A despeito da avaliação positiva da efetividade de algumas dessas medidas, a cobertura era baixa, tendo em vista que, naquele ano, a população total era de 100 milhões e 800 mil habitantes. Quanto às ações assistenciais, em 1971, a FSESP realizava consultas, restaurações, exodontias de decíduos e permanentes e proteções pulpares para a população de escolares, prioritariamente. Destaca-se que a quantidade de exodontias em outros grupos (não detalhado) superava bastante os números no público de escolares. A maior parte das ações era desenvolvida no Nordeste, quando comparada à produção no Norte e em Minas Gerais. (FSESP, 1971)

Outro marco importante nas políticas de saúde bucal de âmbito nacional foi a Lei $n^{\circ}$ 6.050, de 24 de maio de 1974, que dispunha sobre a inclusão da fluoretação das águas de abastecimento nos projetos destinados à construção ou ampliação de sistemas públicos de abastecimento de água em cidades que já possuíam estação de tratamento. (BRASIL, 1974) Seu projeto de lei, o PL 1415/1968, foi submetido, por Baldacci Filho, do Movimento Democrático Brasileiro (MDB) de São Paulo, em 19 de junho de 1968. Um componente da fluoretação das águas foi incluído no Programa Nacional de Alimentação e Nutrição (Pronan), em 1975, sendo a FSESP responsável pela implementação do projeto em cidades com mais de 50 mil habitantes. (PINTO, 1993) Contudo, estudos que analisaram relatórios de acompanhamento da política apontam que não se alcançou os objetivos esperados, tendo em 
vista que, cinco anos após a assinatura da lei, a FSESP havia executado apenas $8 \%$ (PINTO, 1993) ou 38\% (ZANETTI, 1993) das metas previstas.

Citam-se outras políticas de saúde bucal e normas para prestação do serviço odontológico previdenciário como as Orientações de Serviços (ODS) $\mathrm{n}^{\circ}$ 307.1/1975, ${ }^{12} n^{0} 399.67 / 1975,{ }^{13}$ ODS Inamps $n^{0}$ 89/1985 ${ }^{14}$ e o Programa de Prevenção e Diagnóstico Precoce do Câncer Bucal, em 1976. (VIANNA, 1988) O cirurgião-dentista Benedito Elias Waquim participou da implantação deste Programa.

No início da década de 1980, estudo realizado por Vitor Gomes Pinto, ${ }^{15}$ no âmbito do Instituto de Pesquisas Econômicas Aplicadas (IPEA), que apontava para elevada prevalência de cárie dentária na população brasileira ganhou destaque em jornal de grande circulação no Brasil. O título da matéria chamava a atenção que a cárie era um problema de $95 \%$ dos brasileiros. A publicação, que abordou a formação com enfoque técnico-curativo nas faculdades de Odontologia, apontava soluções para o problema da alta prevalência de cárie como a fluoretação das águas de abastecimento público. Algumas das questões em disputa no espaço da saúde bucal podem ser apreendidas a partir da leitura da matéria. (CARIE..., 1980)

O problema "cárie" era priorizado em detrimento de outras doenças bucais, como a doença periodontal e o câncer de boca. A explicação do problema apontava para a responsabilidade dos profissionais, do ensino e da população. Como estratégias de solução, foram apontadas medidas populacionais como a fluoretação das águas de abastecimento público assim como individuais, com a proposta dos selantes dentários. Segundo a matéria, essas soluções são propostas pelo cirurgião-dentista sanitarista.

Já o ponto de vista da Associação Brasileira de Odontologia (ABO), que defendia a Odontologia liberal, manifestava a preocupação com o custo dos materiais odontológicos, criticava o aumento dos preços dos materiais nobres e/ou caros

$12 \operatorname{AODS~}^{\circ}$ 307.1, de 10 de abril de 1975, estendeu aos adultos a possibilidade de obter tratamento preventivo e conservador, segundo recursos financeiros disponíveis e condições locais. As prioridades para tratamento odontológico eram: (i) urgências odontológicas (odontalgias agudas; hemorragias bucais; traumatologia dento-maxilo-facial, estados infecciosos agudos); (ii) tratamentos cirúrgicos (extrações dentárias; demais tratamentos cirúrgicos dento-maxilo-faciais); (iii) tratamentos conservadores (tratamentos estomatológicos, restaurações plásticas em dentes sem comprometimento pulpar; procedimentos profiláticos). (VIANNA, 1988)

13 A ODS SAM n³99.67/1975 normatizava o atendimento de urgência médica e odontológica. (VIANNA, 1988)

14 A ODS Inamps 89/85 estabelecia as normas para a assistência odontológica para as unidades próprias do Inamps. (VIANNA, 1988)

15 Vitor Gomes Pinto nasceu em Porto Alegre, graduou-se como cirurgião-dentista em 1965, com especialização em Saúde Pública pela Universidade de São Paulo (USP), mestrado e doutorado pela mesma instituição. Foi diretor da Divisão Nacional de Saúde Bucal (DNSB) em 1989. 
como o ouro, a prata e o amálgama, reivindicava a regulação estatal do mercado ao Ministro do Planejamento, Delfim Neto. Frente ao ministro das Comunicações, Said Farhat, demandava uma campanha publicitária que esclarecesse a população sobre a importância da prevenção. Ao Congresso Nacional, solicitava a retirada do projeto do deputado Salvador Julianelli, que regulamentava as profissões da área da saúde, o Projeto de Lei n²726/1980 que acusavam de tentar legislar sobre matéria já disciplinada, interferir na autonomia dos profissionais de saúde, tendo em vista que o profissional médico poderia ser supervisor das práticas de todas as outras profissões de saúde.

No Dossiê do PL n 2726/1980 ${ }^{16}$ constam diversos ofícios de entidades de classe de Psicologia, Fisioterapia, Farmácia, Medicina, universidades federais, sindicatos, assembleias legislativas, câmaras de vereadores contra o Projeto de Lei. Destaca-se que não constam documentos de entidades ou instituições que argumentassem pela Odontologia, entretanto, há uma solicitação do deputado Braga Ramos, dentista de formação, para o envio de todos os projetos relativos à Odontologia para a Comissão de Educação e Cultura, da qual fazia parte. A construção social do problema podia estar ligada à luta pela autonomia do campo odontológico. Ainda em 1980, foi lançado o componente de Odontologia do Programa Nacional de Serviços Básicos de Saúde (Prev-Saúde), que foi anunciado, festivamente, na VII Conferência Nacional de Saúde (CNS) e cujas diretrizes tratavam da responsabilidade pública pelos serviços básicos, pela condução e controle de todo o sistema. Abordava, também, a articulação entre as instituições públicas, a descentralização decisória operacional, a integração das ações de promoção, recuperação e reabilitação, a regionalização, a simplificação de técnicas e meios e eficiência administrativa, sem prejuízo da eficácia social e da participação comunitária. (PAIM, 1984)

O Prev-Saúde era um grande Programa de Extensão de Cobertura (PEC), levando em consideração os 40 milhões de brasileiros sem acesso à saúde e a necessidade de controle de certas epidemias, mas, sobretudo, era uma política racionalizadora de custos. O Prev-Saúde era também a expressão de lutas entre grupos empresariais médicos e o governo brasileiro (PAIM, 1984) e passou por reformulações após sua apresentação inicial.

O subprograma odontológico propunha três níveis de prestação de serviços, utilização de pessoal auxiliar com funções expandidas e unidades de atenção elementar. No nível primário, continha ações de prevenção e prestação de cuidados elementares; no secundário, apoio às atividades de primeiro nível e atendimento a 
escolares do primeiro grau; e no terciário, referência para casos complexos e oferta de próteses “sob lucro zero” (PINTO, 1993), ou seja, custeados pelo usuário. Garrafa (1981) considerou que o Prev-Saúde fora conduzido de forma centralizadora e não participativa, o que não trazia muitas esperanças quanto à mudança do acesso e das condições de saúde bucal da população brasileira.

Havia um ponto de vista crítico, que defendia a fluoretação da água como política prioritária, expresso na posição assumida por Volnei Garrafa, ${ }^{17}$ professor na Universidade de Brasília (UnB) e vice-presidente do Centro Brasileiro de Estudos de Saúde do Distrito Federal (CEBES/DF), no I Congresso Internacional de Odontologia de Curitiba, publicado na revista Saúde em Debate. O autor destacava a criação desenfreada de novos cursos de Odontologia no Brasil, sem reflexo na prática odontológica comunitária, mas com aumento da produção de equipamentos sofisticados e técnicas voltadas para a prática privada da Odontologia de Mercado.

A exemplo das universidades e dos órgãos governamentais, as entidades odontológicas também têm se mantido cegas e surdas diante desta situação, apesar das boas intenções de alguns poucos dirigentes mais lúcidos. O dentista Paulo Narvai, ${ }^{18}$ do CEBES de São Paulo, abordou com muita propriedade este aspecto [...]. Lembrou ele que no IX Congresso Paulista de Odontologia, - um dos três maiores do mundo - realizado em janeiro de 1980, as questões fundamentais foram, mais uma vez somente timidamente levantadas. [...] pela enésima vez, foi discutida uma moção de protesto com relação ao não cumprimento da lei que obriga a fluoretação da água de abastecimento público, ação que diminui em cerca de $60 \%$ a incidência da cárie dental. [...] Nestes congressos [...], são invariavelmente programados inúmeros cursos sobre especialidades, ao lado de um isolado, estéril e repetitivo 'debate' sobre 'odontologia comunitária' ou algo assim, para contrabalançar o peso das consciências individuais de um segmento alienado da média burguesia. (GARRAFA, 1981, p. 52)

Devido à crise econômica e aos altos níveis da inflação, o fluxo de pacientes diminuía bastante nos consultórios privados, o que ocasionava multiplicidade de vínculos mal remunerados e o estabelecimento de convênio com firmas ou entidades. (GARRAFA, 1981) No embate pela defesa dos interesses corporativos, mas

17 Doutor em Odontologia. Presidente da Associação dos Docentes da Universidade de Brasília (ADUnB) e vice-presidente do Cebes/DF. (GARRAFA, 1981)

18 Paulo Capel Narvai era cirurgião-dentista, participante do Cebes de São Paulo. Dentista Chefe da Secção de Odontologia Sanitária. Servidor público (dentista) da SES de São Paulo, em 1986. 
sem uma preocupação muito nítida e concreta com as alternativas ao combate dos problemas de saúde bucal da população brasileira, a Associação Brasileira de Odontologia e o Conselho Federal de Odontologia (CFO) defendiam a Odontologia liberal mesmo ao interior da prestação de serviços previdenciários e exerciam uma posição dominante no campo odontológico. Em muitos momentos, os problemas bucais se tornavam argumentos para a defesa da Odontologia liberal e para assegurar os interesses das entidades de classe. Na ocasião da solenidade de outorga da "Medalha Luis Cesar Panain", medalha de honra ao mérito a dentistas, pelo Conselho Regional de Odontologia de São Paulo (CRO-SP), o presidente do Conselho Federal de Odontologia, Fernando de Souza Lapa, ${ }^{19}$ se dirigiu ao Ministro da Previdência Social Jair Rodrigues, que também era cirurgião-dentista, sobre a importância da criação de um departamento específico de Odontologia no âmbito da previdência, na luta pela autonomia do campo odontológico.

Transformar a Coordenadoria Odontológica do Inamps em Departamento, pois, caso contrário, qualquer plano de saúde bucal estará fadado a falecer antes mesmo do seu nascimento. Não iremos lhe pedir nada. Apenas que entregue as rédeas da Odontologia à própria Odontologia. (LAPA, 1980, p. 7)

Apoiado pelo presidente da Associação Brasileira de Odontologia (ABO), Paulo Frenkel, ${ }^{20}$ e pelo presidente da Federação Nacional dos Odontologistas

19 Fernando de Souza Lapa era "Especialista em Cirurgia e Traumatologia Buco - Maxilo Facial e em Ortodontia, recebeu o tìtulo de Sócio-BenemĖrito do Colégio Brasileiro de CTBMF. Foi responsável pelo setor de Ortodontia e Cirurgia Buco-Maxilo Facial da disciplina de Cirurgia Plástica e Queimaduras do Hospital das Clínicas da Faculdade de Medicina da USP, desde 1963. Doutor em ciências pela Faculdade de Medicina da Universidade de S „o Paulo, aprovado com nota máxima. Foi o primeiro Cirurgião-Dentista a defender tese de Doutoramento em Cadeira de Cirurgia da Faculdade de Medicina da USP. Era doutor em Odontologia pela PUC do Rio Grande do Sul, Livre Docente em Cirurgia e Traumatologia Buco-Maxilo Facial da mesma faculdade, professor extranumerário do curso regular de Medicina da USP, desde 1961, professor titular da especialidade na Faculdade de Odontologia de Santo Amaro (OSEC) e da Faculdade de Odontologia da Zona Leste e membro de diversas Comissões Examinadoras de Concursos para Livre Docíncia. Foi membro de inúmeras Associaçõıes como a Federation Dentarie Internacional, a British Association for Maxilo Facial Surgery e a Sociedade Argentina de Cirurgia y Traumatologia Buco Maxilo-Facial. Seu enorme currìculo compunha-se de mais de 400 tìtulos. [...] Foi o segundo presidente do Conselho Regional de Odontologia de $S_{n}$ o Paulo, tendo construído e ampliado a sede da avenida Paulista e dirigido a entidade de 1972 a 1976 [...]. No CFO, deu ênfase às especialidades, criando concursos para habilitação de profissionais, através de bancas de professores eméritos [...]. Reformou e informatizou a sede do Rio de Janeiro". (FALECIMENTO..., 2004, p. 11)

20 Paulo Frenkel era cirurgião-dentista, presidiu a ABO. Na sua gestão, em 1981, organizou o congresso da FDI World Dental Federation, no Rio de Janeiro. Atuou na FNO. Foi $2^{\circ}$ Secretário da Confederação Nacional das Profissões Liberais de 1972 a 1975. 
(FNO), Joaquim Arsênio Benedicto Ottoni Junior, ${ }^{21}$ Lapa citou a iniciativa do referido Ministério em montar uma comissão interministerial para estudar os problemas de saúde bucal e montar um plano de assistência à saúde. Entretanto, defendia a reivindicação das entidades de classe que sua participação neste movimento fosse assegurada, assim como, maior autonomia no setor de Odontologia da Previdência.

O presidente do CFO justificava que não era apenas o Brasil que apresentava um quadro alarmante de falta de acesso aos serviços odontológicos, recusando a suposição de que os cirurgiões-dentistas seriam os únicos responsáveis pela situação. Também nos Estados Unidos, a situação não conseguia ser contornada. Adicionava o interesse das entidades de classe odontológica por "fazer alguma coisa em benefício da comunidade brasileira” através da Previdência Social. Novamente, é possível constatar aspectos da construção da doença cárie como um problema social.

A posição defendida pelo presidente do CFO reivindicava para a Odontologia o mesmo status da Medicina caracterizando-as como “irmãs-gêmeas", mas também defendia a conquista de espaço profissional e autonomia do campo odontológico, ao passo em que afirmava que a Odontologia necessitava ser independente, autônoma e separada, lutando pela equivalência à Medicina hegemônica, e criticava a formação de pessoal auxiliar e o aumento indiscriminado de profissionais.

Ele opunha também as associações profissionais à tecnocracia, diferenciando, assim, o ponto de vista legitimo da Odontologia e das suas associações, daquele da "tecnocracia" e dos planos de gabinete. Esta oposição pode ser caracterizada como o enfrentamento entre o ponto de vista liberal e o ponto de vista do campo burocrático dos sanitaristas. O financiamento das ações para os serviços odontológicos se concentrava na Previdência Social, direcionado aos trabalhadores e seus dependentes.

Em entrevista, Vitor Gomes Pinto ${ }^{22}$ conta que os dentistas se dirigiam à Previdência Social como "a toda poderosa", pois o financiamento das ações para saúde bucal pelo Ministério da Saúde, no início da década de 1980, era praticamente inexistente. No ano seguinte, 1981, as pressões por parte das entidades de classe continuaram sobre o ministro da Previdência Social, Jair Soares, por maior autonomia para o setor odontológico dentro da previdência. A plenária final do V Congresso Internacional de Odontologia, realizado no Rio de Janeiro, no mesmo ano,

21 Joaquim Arsênio Benedicto Ottoni Júnior foi presidente da Federação Nacional dos Odontologistas (FNO) e conselheiro fiscal da Confederação Nacional das Profissões Liberais de 1972 a 1975.

Entrevista concedida à autora, Brasília, em 21 ago. 2014. 
apontou que os dentifrícios comercializados no Brasil não continham flúor e desta forma, não exerciam seu papel na prevenção das cáries, servindo apenas para facilitar a escovação e melhorar o hálito. (CIRURGIÕES-DENTISTAS..., 1981) Ademais, criticavam a efemeridade do Prev-Saúde, criado em 1980, propunham uma Odontologia Social ${ }^{23}$ e criticavam que a oferta de serviços odontológicos consistia nesse programa e não em um departamento. Com forte domínio da Odontologia de mercado, criticavam também o monopólio da indústria internacional na produção de insumos odontológicos e sugeriam a importância do investimento na indústria nacional. (CIRURGIÕES-DENTISTAS..., 1981)

No mesmo ano, ocorreu o I Encontro Internacional de Odontologia, em Curitiba no qual Volnei Garrafa mostrava que o Brasil possuía o mesmo número de dentistas dos Estados Unidos da América, entretanto, com distribuição muito desigual. Criticava também a formação em Odontologia e a prestação de serviços públicos e privados.

A Odontologia, no Brasil, é ineficaz e ineficiente; descoordenada; os seus recursos humanos são mal distribuídos, pois há uma enorme concentração de dentistas nas grandes cidades; a cobertura de assistência que ela oferece é muito baixa; está numa faixa de alta complexidade e sofisticação; desenvolve exclusivamente um enfoque curativo, sem nenhuma preocupação preventiva; seu caráter é mercantilista e monopolista. (BRASIL..., 1981, p. 26)

Nessa mesma publicação, o autor apontava para a omissão enquanto a política de saúde bucal ${ }^{24}$ que "[...] encarasse a questão odontológica dentro da sua devida importância” (BRASIL..., 1981, p. 26), ratificada por outra publicação no jornal que tratava do ponto de vista dos usuários de consultórios privados, apontando que, devido à crise, o paciente passava a frequentar consultórios populares. (DENTISTAS..., 1981) Esse ponto de vista formulado por Volnei Garrafa, cuja trajetória dominante havia sido no interior do espaço da Saúde Coletiva em formação, é semelhante à crítica realizada por muitos sanitaristas ao Sistema de Saúde vigente à época.

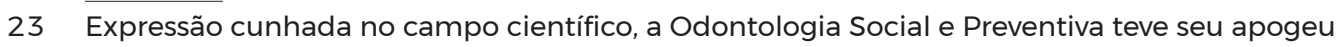
na ditadura militar, no período entre 1968 e 1978, e seu declínio na década de 1980. Tem como base as formulações da Odontologia Sanitária. (NARVAI, 2006)

24 Cumpre ressaltar que, segundo o conceito de política de saúde adotado no presente estudo, sempre há uma política de saúde, sendo traduzida em ação ou omissão do Estado. Neste caso, a política de saúde bucal seria a omissão. 
O presidente do Conselho Regional de Odontologia de São Paulo, Wilson Garoni, ratificava que “[...] o atendimento dentário não está ao alcance da população". (DENTISTAS..., 1981c) A grande prevalência de cárie entre crianças de 6 a 14 anos foi amplamente discutida, assim como a inexistência de um programa de prevenção dedicado a esta faixa etária. Tratava, ainda, das insuficiências dos Ministérios da Saúde e da Previdência chegando à crítica moral.

O Ministério da Saúde não tinha nenhum setor, nenhum departamento, nenhuma pessoa para atender telefone, no que se refere ao setor odontológico. Já a Coordenação odontológica do Inamps, que desenvolve um trabalhão do tipo tapa buraco, de caráter mutilador, é dirigida por pessoas incompetentes e alienadas. (BRASIL..., 1981)

A simplificação do atendimento, que originou a corrente teórica da Odontologia Simplificada, ${ }^{25}$ era apontada como uma das alternativas para solucionar os problemas crescentes que os dentistas vinham enfrentando de mercado de trabalho. A parcela de $5 \%$ da população que custeava seu tratamento através de desembolso direto estava muito saturada. (ODONTOLOGIA..., 1981)

O precário programa de fluoretação das águas também foi alvo de críticas. Em outro evento, em 1982, no IV Encontro Municipal de Odontologia Comunitária, Vitor Gomes Pinto também criticava a ausência de uma política para enfrentar os problemas de saúde bucal da população brasileira. (ODONTOLOGIA..., 1981)

Pinto também defendeu a divisão de tarefas no processo de trabalho em saúde bucal com pessoal auxiliar, em outro evento científico, o $1^{\circ}$ Congresso de Odontologia do Vale do Parnaíba. Nos Anais da VII Conferência Nacional de Saúde, em 1980, já constava a preparação de recursos humanos de nível auxiliar e técnico, além de uma recomendação, em caráter urgente, acerca da formação de um "técnico dental operador”. Ressalta-se que a introdução do pessoal auxiliar no Brasil vem sendo experimentada desde 1950, com os Serviços Especiais de Saúde Pública (SESP). (FAQUIM; CARNUT, 2012) A partir da década de 1980, o processo de muitas disputas ao interior do campo odontológico seguiu pelas atividades a serem desempenhadas no processo de trabalho, destacando-se as tomadas de posição das associações de classe que assumiam lugar mais conservadora defendendo que o técnico poderia assumir o lugar do Cirurgião-Dentista (CD) ou que um CD ficaria

25 A Odontologia Simplificada surge no discurso odontológico nos anos 1970. A expressão vinha sendo utilizada na América Latina e era utilizada para tratar da padronização, diminuição dos passos, eliminação do supérfluo, tornando mais simples e barata a Odontologia, sem alterara a qualidade. Assim, tornava viável os Programas de Extensão de Cobertura. (NARVAl, 1994) 
responsável por supervisionar uma quantidade muito grande de pessoal auxiliar, o que impactaria no mercado de trabalho para ele.

\section{Plano de reorientação da assistência odontológica (Praod) e ações do Inamps}

Em 1982, foi lançado o "pacote da previdência” através de um pronunciamento do presidente da República João Figueiredo, em rede nacional de televisão. Este "pacote" tratava do reordenamento dos serviços de saúde, da substituição do pagamento por ato pelo pagamento por tratamento e da expansão dos convênios com a medicina de grupo. (PAIM, 1984) Nesse momento de crise da Previdência, foi criado o Conselho Consultivo de Administração de Saúde Previdenciária (Conasp), através do Decreto $n^{\circ} 86.329$, de 2 de setembro de 1981. Dentro do plano do Conasp, havia a proposta do Programa de Ações Integradas de Saúde (AIS) que propiciava o convênio de municípios com o Inamps. (PIRES, 2004)

O Plano de Reorientação da Assistência Odontológica (Praod) foi editado em 1983, pelo Ministério da Previdência e Assistência Social (MPAS), na gestão no ministro Hélio Beltrão que sucedeu a de Jair Soares. Este documento foi elaborado por um grupo de cirurgiões-dentistas que integravam a Comissão de Especialistas em Odontologia do Conasp, responsável por "apreciar e apresentar princípios e questões fundamentais da assistência odontológica em nosso meio, e como consequência, de seu estudo crítico das propostas e dos relatórios então apreciados [...]”. (BRASIL, 1983) (Figura 2).

A Comissão de Especialistas foi instituída pela Portaria Inamps/PR n ${ }^{\circ} 855 / 82$, de 24 de novembro de 1982, sendo constituída por: Paulo da Silva Freire, ${ }^{26}$ coordenador da assistência odontológica do Instituto Nacional de Assistência Médica da Previdência Social (Inamps); Olympio Faissol Pinto, odontólogo; Alfredo Reis Viegas, professor da USP; Eugênio Vilaça Mendes, professor da Universidade de Belo Horizonte; Edrizio Barbosa Pinto, da Associação Brasileira de Ensino Odontológico; Solón Magalhães Vianna, odontólogo; Waldir Viana das Neves, da FSESP; Mercio de Azevedo Ferreira, do Ministério da Saúde; Paulo Monteiro Freitas, da Federação Nacional dos Odontologistas; Manoel Tompson de Araújo, da Associação Brasileira de Odontologia; José Roberto Pontes, do Sindicato dos Odontologistas

26 Paulo da Silva Freire, cirurgião-dentista, integrou a FSESP. Professor da Universidade Federal Fluminense (UFF), foi diretor da seção de Odontologia no Inamps. Integrou a diretoria da Associação Brasileira de Ensino Odontológico de 1971 a 1974. 
do Rio de Janeiro; Fernando de Souza, do Conselho Federal de Odontologia; Sérgio Pereira, da Secretaria de Educação do Distrito Federal; José Dilson Vasconcelos de Menezes, do Inamps/CE; e Vitor Gomes Pinto, do IPEA. Um dos participantes da comissão retrata o caráter das mudanças ocorridas no âmbito da Previdência e não apenas na Odontologia e fala sobre o convite para Paulo Freire se tornar o coordenador de odontologia do Inamps.

[...] No tempo do Aloysio, foi nessa época que o Inamps no movimento de mudança geral. O grupo do Inamps que era diferente do grupo da ENSP, Sergio Arouca e etc. O grupo do Inamps, era esse grupo do Eleutério Rodriguez Neto, do tempo do Aloysio Sales que era um médico famoso [...] Isso gerou aquela proposta de mudança da previdência social da saúde. E aí eu participei desse grupo onde estava o Paulo [da Silva] Freire, quando o Inamps formula essa proposta de saúde bucal. [...] Nesse tempo do Paulo Freire teve esse movimento que não foi só da odontologia foi um movimento de reforma da previdência social na saúde. [...] tem uma série de medidas que são editadas com modificações de procedimentos com o perfil do serviço. Lembro do Alfredo Reis Viegas que você tem aí também. Ele éfundamental. (Entrevisado 14, dentista, consultor)

O Entrevistado 14 fez uma diferenciação entre os grupos do Inamps e da Escola Nacional de Saúde Pública Sérgio Arouca (ENSP) que se situavam em equivalência com o grupo de fundadores da Saúde Coletiva no Brasil, sendo adotada como uma reforma ampla aquela desenvolvida pelo grupo no âmbito do Plano Conasp, tendo sido considerada enquanto medida racionalizadora por Paim (2008). A mídia impressa noticiou o lançamento do Praod como o plano que modificaria a assistência odontológica no Brasil, contudo, este não trazia nenhuma novidade em seu conteúdo. O plano era retratado como a expressão das reivindicações feitas pelos sanitaristas da época. (PRONTO..., 1983)

O documento incorporava, principalmente, os pontos de vista da burocracia através dos sanitaristas do IPEA. Ademais, incorporava o ponto de vista defendido por Alfredo Reis Viegas da Faculdade de Saúde Pública da USP, mas também da Odontologia de liberal através das entidades de classe como CFO e ABO. Autores apontam que o modelo da assistência odontológica previdenciária sintetizou o modelo da Odontologia de mercado ${ }^{27}$ inserido no aparelho estatal. Outro ponto de

27 A Odontologia de mercado deriva da Odontologia liberal e se baseia na assistência odontológica ao indivíduo doente, realizada pelo cirurgião-dentista no âmbito do consultório. (NARVAI, 1994) Predomina no setor privado, mas, também, no serviço público, através de sua essência na base biológica e individual, sendo orgânico ao modo de produção capitalista que transforma os cuidados de saúde em mercadoria. (NARVAl, 2006) 
destaque foi a dificuldade enfrentada pela comissão de especialistas em obter dados para subsidiar o plano. (NARVAI; FRAZÃO, 2008a, 2008b; PRONTO..., 1983)

Figura 2 - Capa do documento Plano de Reorientação da Assistência Odontológica (Praod)/Ministério da Previdência e Assistência Social ${ }^{28}$

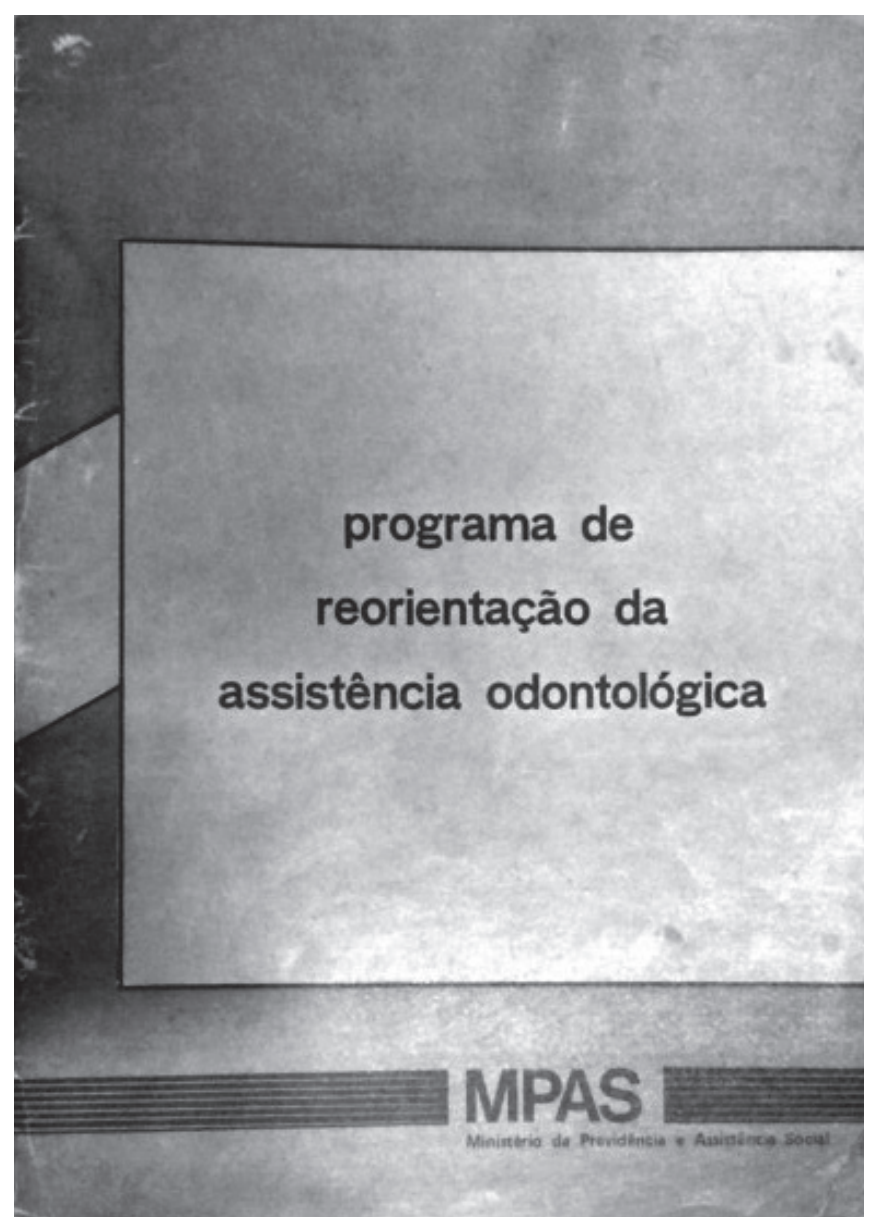

Fonte: Brasil (1983).

Na apresentação assinada pelo presidente do Conasp, Aloysio de Sales Fonseca, o documento é caracterizado como um programa em que "dominam as ações e políticas administrativas e técnicas, todas iluminadas pelos critérios de coparticipação, integração, regionalização, hierarquização e descentralização, de modo a assegurar maior cobertura e eficiência da Instituição e racionalização das despesas”. (BRASIL, 1983) 
O Praod tinha como objetivos/pressupostos:

- estender a cobertura dos serviços odontológicos básicos ${ }^{29}$ a toda a população;

- reduzir a incidência das doenças bucais de maior expressão epidemiológica através da aplicação racional de métodos de massa e de atenção individual aos grupos prioritários;

- aumentar a produtividade do sistema, buscando uma melhor relação custo/benefício;

- integrar ao sistema os órgãos públicos federais, estaduais e municipais assim como as instituições e entidades de ensino beneficentes e organizações sindicais e patronais, proporcionando uma descentralização das atividades e maiores possibilidades de atendimento. (BRASIL, 1983)

Essas diretrizes foram em parte incorporadas ao Sistema Único de Saúde. Seus princípios norteadores eram:

- integração das ações de prevenção, recuperação e de educação em saúde;

- reorientação do sistema, privilegiando a ampliação das ações básicas de saúde;

- integração dos organismos federais de prestação direta de serviços de saúde com os de âmbito estadual e municipal, de ensino, instituições pias e beneficentes e organizações sindicais e patronais;

- pleno aproveitamento da capacidade ociosa e racionalização de procedimentos técnico-administrativos;

- efetiva participação comunitária nos programas de saúde da boca;

- definição clara do papel do setor privado vinculado a programas oficiais;

- planejamento e ações de saúde segundo os princípios de regionalização e hierarquização dos serviços e de racionalização e simplificação dos métodos de trabalho. (BRASIL, 1983)

A comissão retrata a importância do flúor no combate à doença bucal mais prevalente à época, a cárie dental, dos equipamentos simplificados e da utilização de pessoal auxiliar. Alguns princípios gerais eram semelhantes aos do Prev-Saúde, Interiorização das Ações de Saúde e Saneamento (Piass), mas em caráter ainda restrito. 
como a regionalização do sistema e a hierarquização dos serviços. (VIANNA, 1988) Algumas políticas públicas foram abordadas, como os primeiros projetos de utilização de equipamentos simplificados e de pessoal auxiliar em Aimorés, Minas Gerais, em 1952, pela FSESP, direcionado à população entendida como mais vulnerável, na faixa etária de 6 a 12 anos, o tratamento incremental, a experiência pioneira do processo de fluoretação das águas em Baixo Gandú, Espírito Santo, em 1953, e os programas de atenção ao escolar.

O Praod retrata uma ausência de valorização histórica da saúde bucal e o baixo financiamento para as ações. Compara o Brasil com outros países quanto à prevalência da cárie dentária apontando para a difícil situação que o país enfrentava com média de dentes cariados, perdidos e obturados na população examinada com índice CPO-D de 7,2. Países como a Tanzânia, Libéria tinham CPO-D de 0,6, na Inglaterra era 3,1 e no México era 5,2. (BRASIL, 1983)

Assim, a cárie dental era caraterizada, nos anos 1980, como principal problema de saúde bucal da população brasileira, seguida pela doença periodontal, as deformidades dento-faciais, lábio leporino e fenda palatina e câncer de boca. Não existia um inquérito epidemiológico oficial específico de saúde bucal no Brasil, em 1983, e os dados oriundos de pesquisas locais ou estaduais realizadas por outros autores utilizados foram trabalhados por Vitor Gomes Pinto, integrante da comissão, no âmbito do IPEA, em 1983, oriundos principalmente de São Paulo, mas também Bahia, Espírito Santo, Distrito Federal, Minas Gerais, Paraíba, Pernambuco, Rio Grande do Sul e Rio Grande do Norte. O Plano já indicava um grande aumento do CPO-D no decorrer das faixas etárias com um aumento exponencial do componente perdido enquanto uma prática predominante no exercício da Odontologia. Outro quadro que tinha como fonte estudos do prof. Alfredo Reis Viegas sinalizava uma demanda por tratamento odontológico de milhões de pessoas, com base na população brasileira de 1980.

Caracterizando o modelo da assistência odontológica no Brasil, o Inamps, principal instituição pública prestadora de serviços odontológicos no país, era responsável por $58,5 \%$ de todos os gastos públicos efetuados em 1981. (BRASIL, 1983) Neste ano, a saúde bucal representava 3,19\% dos gastos públicos em saúde (BRASIL, 1983), entretanto, o setor público contribuiu com apenas $18,2 \%$ dos gastos em saúde bucal, cabendo ao setor privado a maioria dos dispêndios pessoais e institucionais. (BRASIL, 1983) A necessidade do investimento em prevenção era justificada pelo volumoso montante estimado para o tratamento curativo no período, sendo a atividade preventiva urgente para a redução dos gastos assistenciais. Dentre as modalidades de prestação dos serviços odontológicos pelo Inamps, as 
principais, segundo o número de consultas e os gastos efetuados, eram a modalidade de serviços próprios e de credenciamento de pessoas físicas.

Em 1982, Paulo da Silva Freire, dentista que fez parte da FSESP, assumiu o cargo de Coordenador da Assistência Odontológica do Inamps, através da Portaria PT/PR 791, de 10 de setembro de 1982. Assim, tal como a “[...] exportação do Coordenador de Odontologia da FSesp” para o Inamps, "as soluções gerenciais para as deficiências sanitário-bucal começaram a tomar orientações sespianas”. (ZANETTI, 1993, p. 70)

A participação de entidades na redação do Praod é controversa. Os entrevistados 12 e 26 do programa afirmam ter contado com a participação de representantes de associações. Já segundo o depoimento do Entrevistado 4, o documento havia sido construído em caráter sigiloso e editado verticalmente sem a participação de órgãos da gestão, como as coordenações estaduais.

O Praod foi escrito no IPEA e considerado como contendo "os avanços possíveis no período", tendo em conta "o que podia ser compreendido pela coordenação de odontologia do Inamps” e o estágio das discussões no Sistema de Saúde. (PINTO, 1983, p. 112) Devido a influência dos autores, o documento traz características da saúde pública vigente no período, mesmo sendo uma publicação da previdência. Este documento apontava para a limitação do Inamps em atender às demandas da população brasileira e propunha o atendimento a grupos vulneráveis. A necessidade das ações de prevenção era trazida como um imperativo de parceria com outros ministérios, já que o Ministério da Saúde, à época, não era responsável pelas ações assistenciais, cabendo ao Ministério da Previdência. Os cidadãos que não trabalhavam, não tinham acesso à saúde. Este texto é tido como de grande avanço para a época por autores, entretanto, não há análises mais detalhadas sobre ele.

Ainda em 1983, o Inamps, através do seu coordenador específico de Odontologia, Paulo Freire, celebrou um convênio de experiência docente-assistencial com a Pontifícia Universidade Católica de Minas Gerais (PUC-Minas). Como Paulo Freire havia sido da FSESP e Mário Chaves foi um apoiador deste projeto, a Universidade contou com recurso do Inamps. Através deste projeto propõe-se um novo modelo de Odontologia simplificada, inspirado no Programa Integrado de Saúde do Escolar (PISE), elaborado por Sérgio Pereira, no Distrito Federal. A experiência serviu de modelo para muitas faculdades de Odontologia que conseguiram reduzir a quantidade de extrações em comparação ao praticado nos serviços do Inamps, segundo o Entrevistado 14. O Departamento de Odontologia da PUC-Minas desenvolveu importante experiência de reorientação do ensino odontológico. Defendia-se o desenvolvimento da Odontologia Integral, mas, na prática, reproduzia-se as 
propostas da Odontologia sanitária/social e comunitária/simplificada. (NARVAI, 1994)

No ano seguinte, 1984, o problema cárie permanecia figurando como o principal, na mídia impressa, que continuava a trazer matérias de eventos científicos e pautas acerca do enorme número de desdentados no Brasil, aproximadamente 10 milhões de pessoas, em 1984. (O BRASIL..., 1984) Acerca da doença cárie, Entrevistado 1 ressalta:

[...] o flúor estava começando, então a cárie avançava. Você fazia uma 'O' [restauração oclusal], e em seguida ela [aumentava] e pegava vestibular. Quer dizer, aquilo era um negócio avassalador. Quando você via, o dente estava comprometido [...] A cárie era o fenômeno biológico mais avassalador.

Em 1984, foi assinado um convênio entre os Ministérios da Previdência Social, Saúde e Educação a fim de incluir a assistência odontológica no plano de integração das ações básicas de saúde do Conasp. O programa foi considerado como a "redenção da saúde oral para o povo brasileiro", pelo ministro da Educação, que solicitou o atendimento a escolares também no período de férias. (O BRASIL..., 1984) O Inamps também investiu em um Programa de Selantes Oclusais, entretanto, não obteve muito sucesso, apesar do investimento em grandes quantidades de material. (PINTO, 1993)

\section{Políticas de Saúde Bucal no âmbito do Instituto de Pesquisas Econômicas Aplicadas (IPEA)}

Na saúde bucal, as principais políticas conduzidas pelo Instituto de Pesquisas Econômicas Aplicadas (IPEA) foram a fluoretação das águas de abastecimento público, que ficou sob responsabilidade da FSESP e monitorada pelo IPEA, com financiamento do Banco Nacional da Habitação (BNH), e a saúde do escolar, que foi alocada no Ministério da Educação, também monitorada pelo Instituto. A fonte de financiamento destas ações foi o Fundo de Apoio ao Desenvolvimento Social (Finsocial).

A proposta para a saúde bucal, no Programa Nacional financiado pelo Finsocial, previa pequena extensão de cobertura e estimava beneficiar até 30 milhões de pessoas que, somadas aos 25 milhões que já estavam protegidas, atingiria $46 \%$ da população brasileira no início da década de 1980. (VIANNA; PINTO, 1983) Este projeto adotava metas menos pretensiosas que o anterior programa de fluoretação, em parceria Instituto Nacional de Alimentação e Nutrição (INAN) e FSESP, e bus- 
cava reativar a operacionalização dos sistemas paralisados e estender a fluoretação em 35 cidades. (VIANNA, 1988) As estratégias de implantação envolviam os recursos oriundos do Finsocial que, mediante convênio com o BNH, teria os recursos repassados com o Banco Nacional de Desenvolvimento Econômico e Social (BNDES). No acompanhamento do projeto, estavam a Secretaria de Planejamento (IPEA/BNDES), o BNDES e o Ministério da Saúde, através do GT-Odonto ${ }^{30}$. Ademais, $5 \%$ do valor do Programa se destinava ao GT-Odonto, Comitê de Saneamento do Ministério da Saúde, FSESP e Secretarias de Saúde, para estudos epidemiológicos, controle da água e pesquisas de métodos alternativos de prevenção da cárie dental com recursos próprios do Ministério da Saúde. (VIANNA; PINTO, 1983)

Quanto ao programa de saúde escolar, foram estabelecidas como ações básicas: a inscrição do aluno - primeiro contato do indivíduo com o responsável pelas ações de saúde na escola para elaboração da sua ficha de saúde, com anotações de caráter geral; vigilância epidemiológica - manter a vigilância sobre a saúde das crianças e tomar as medidas adequadas, principalmente nos casos de doenças transmissíveis; visitação domiciliar; primeiro atendimento - problemas de saúde surgidos na escola, prestação de primeiros socorros e curativos em acidentes; identificação de problemas mais comuns - estado geral, pele e couro cabeludo, boca, olhos, ouvidos, comportamento; educação em saúde e controle das condições de saneamento Especificamente na saúde bucal, o Programa propunha priorização do escolar do $1^{\circ}$ grau e a utilização do sistema incremental, tendo como alicerces a formação de pessoal de nível superior, técnico e elementar, além da Odontologia Simplificada, que propunha o controle sobre o uso de procedimentos sofisticados. (VIANNA; PIOLA; PINTO, 1983) O Programa envolvia a participação direta do Ministério da Educação e Cultura (MEC), da Secretaria de Planejamento e Assuntos Econômicos (Seplan), BNDES e IPEA, MS e MPAS, conforme citado anteriormente.

Diante do recurso citado, que foi alocado no Ministério da Saúde, o órgão lança uma proposta de utilização de recursos envolvendo levantamento epidemiológico sobre saúde bucal, pesquisa sobre métodos alternativos de fluoretação, implementação da fluoretação da água em localidades do Nordeste, atividades de coordenação e apoio a nível central, educação em saúde e Vigilância Sanitária. (VIANNA, 1988) As ações de Vigilância Sanitária foram estruturadas em cada estado, com exceção de Minas Gerais, nos Grupos Especiais de Controle da Fluoretação (Gecof). Já as ações de educação em saúde ficaram a cargo da Divisão Nacional de Educação Sanitária e a Divisão Nacional de Ecologia Humana e Saúde Ambiental 
do Ministério da Saúde ficou responsável pelo controle dos níveis de fluoretação das águas para o consumo humano. (VIANNA, 1988) As pesquisas trataram sobre métodos alternativos em estações de tratamento de água e sobre a viabilidade da fluoretação do sal no Brasil. ${ }^{31}$ (ZANETTI, 1993)

Benedito Elias Waquim ${ }^{32}$ que participou do GT-Odonto comentou as ações desenvolvidas no âmbito desses programas:

Nós conseguimos um recurso do Banco Nacional de Desenvolvimento Social, através da Caixa Econômica, e a partir daí, reunimos todos os presidentes, diretores, técnicos, engenheiro técnico das companhias de abastecimento de água do pais [...] fizemos o Primeiro Congresso Internacional de Odontologia voltado para a qualidade da água, para o consumo e foi a primeira vez que a odontologia se reuniu com engenheiros [...] Eu percorri todas as capitais do Brasil, reunimos o secretário de saúde do estados ou do município, ABO, o Conselho, representantes da companhia de abastecimento de água, representante da Caixa Econômica Federal e tinha mais gente. Esse grupo tinha a responsabilidade de receber o recurso da Caixa Econômica e comprar oflúor [...] além da fluoretação de água de abastecimento público, o Vitor [Gomes Pinto] estava na frente e nós fizemoso primeiro levantamento epidemiológico da carie dental no Brasil.

Assim, o primeiro inquérito epidemiológico específico de Saúde Bucal foi coordenado pelo IPEA, em 1986 (PINTO, 2014), e, no nível nacional, foi realizado em 16 cidades, apenas em área urbana, tendo sido priorizadas as cidades que tivessem boa representatividade regional e que possuíssem representação da FSESP. (BRASIL, 1986c) Devido à escassez de recursos, limitou-se o inquérito aos grupos etários 6-12, 15-19, 34-44 e 50-59 anos e os problemas investigados foram:

- cárie dental - 6,65 CPO-D aos 12 anos (um dos maiores do mundo);

- problemas periodontais;

- uso e necessidade de prótese; e (iv) demanda por serviços. (BRASIL, 1986c)

31 Entrevista concedida à autora por Benedito Elias Waquim em dezembro de 2014.

32 Benedito Elias Waquim nasceu em São Luís (MA), onde concluiu seu curso de graduação em Odontologia. Fez residência no Hospital do Câncer no Instituto Nacional de Câncer (INCA). Foi consultor do Ministério da Saúde, desde 1977, depois, tornou-se o responsável pela implantação do Programa Nacional de Prevenção e Diagnóstico do Câncer de Boca da Divisão em Educação, tendo produzido dois manuais. Participou do GT-Odonto, da Divisão Nacional de Saúde Bucal e foi Coordenador Nacional de Saúde Bucal na década de 1990. Entrevista concedida à autora, Salvador, 2014. 